\title{
Plasma surface carburizing with graphite paste
}

\author{
A. E. Balanovskii, Vu Van Huy ${ }^{\dagger}$ \\ thuy241989@gmail.com
}

Irkutsk National Research Technical University, 83 Lermontov St., 664074, Irkutsk, Russia

The paper considers a new technology of plasma surface carburization using graphite-containing pastes made from liquid glass and graphite. The use of this type of coating along with a new composition of the plasma-forming gas (a mixture of argon and carbon dioxide) allows one to saturate the metal surface with carbon without surface melting. It is established that during the time interval of plasma action, $0.1-1 \mathrm{sec}$, the surface layer is saturated with carbon to the level of white iron concentration. Microstructures and characteristics of the metal surface after plasma cementation have been studied. The main parameters of the cemented layer are determined: the depth of the cemented layer amounts $35-250 \mu \mathrm{m}$ and the microhardness up to $12000 \mathrm{MPa}$. Depending on the composition of the coating and the cooling rate, $\gamma \rightarrow \alpha-$ transformation can result in the formation of a wide range of structural components. The morphological composition obtained in the process of plasma surface carburization is very diverse and specific that is due to the distribution of carbon in the volume of material in the plasma treatment zone, the speed parameters of heating and cooling, and the composition of the graphite coating. Each phase and structure present in the hardened layer (retained austenite, cementite, martensite, ledeburite) has its own varieties. The cemented layer consists of two zones, where the first zone with significant carbon supersaturation (white iron structure) is formed due to frontal diffusion of carbon (layer structure: ledeburite, austenite, martensite). The second zone is formed due to intensive or reactive diffusion, in this zone the carbon concentration gradually approaches the initial one. The band structure of the cemented surface layer clearly indicates on a gradient of carbon concentration in the steel.

Keywords: plasma surface hardening of metals, carbonaceous paste, plasma cementation, diffusion, microhardness, cemented layer.

\section{Плазменная поверхностная цементация с использованием графитового покрытия}

\author{
Балановский А.Е., Vu Van Huy
}

Иркутский национальный исследовательский технический университет, ул. Лермонтова 83, 664074, г. Иркутск, Россия

Рассмотрена новая технология выполнения плазменной поверхностной цементации с использованием графитосодержащих паст, приготовленных из жидкого стекла и графита. Применение данного типа покрытия вместе в сочетании с новым составом плазмообразующего газа (смесь аргона и углекислого газа) позволяет проводить насыщение поверхности металла углеродом без оплавления. Установлено, что за время воздействия плазмы 0,1-1 с поверхностный слой насыщается углеродом до уровня концентрации белого чугуна. Изучены микроструктуры и характеристики поверхности металла после плазменной цементации. Определены основные параметры цементированного слоя: глубина цементированного слоя составляет 35-250 мкм, микротвердость до 12000 МПа. В зависимости от состава покрытия и скорости охлаждения $\gamma \rightarrow \alpha-$ превращение может завершиться формированием широкого спектра структурных составляющих. Морфологический состав, получаемый в процессе плазменной поверхностной цементации очень разнообразный и специфический, что обусловлено распределением углерода по объёму материала в зоне плазменной обработки, скоростными параметрами нагрева и охлаждения и составом графитового покрытия. Каждая фаза и структура, присутствующая в упрочненном слое (остаточный аустенит, цементит, мартенсит, ледебурит) имеет свои разновидности. Цементированный слой состоит из двух зон, где первая зона со значительным пересыщением по углероду (структура белого чугуна) формирующаяся за счет фронтальной диффузии углерода (структура слоя: ледебурит, остаточный аустенит, мартенсит). Вторая зона формируется за счет интенсивной или реакционной диффузии, в данной зоне концентрация углерода постепенно приближается к исходной. Зонное строение цементированного поверхностного слоя стали однозначно свидетельствует о градиенте концентрации углерода в стали.

Ключевые слова: плазменное поверхностное упрочнение металлов, углеродосодержащая паста, плазменная цементация, диффузия, микротвердость, цементированный слой. 


\section{1. Введение}

В последние годы в промышленности среди существующих методов поверхностного упрочнения: закалка ТВЧ, лазерная закалка, наплавка, металлизация т. д., получают известность новые перспективные методы поверхностного упрочнения - плазменная закалка, которые не только эффективно снижают степень изнашивания поверхности, но доступны к практическому применению [1-2]. Если в процессе плазменной поверхностной закалки вместе с нагревом протекает насыщения поверхности углеродом, то такая разновидность поверхностного упрочнения называется плазменной цементацией. Поверхностная цементация с применением углеродосодержащих паст и обмазок рассмотрена в работах $[2,3]$. Сущность данного вида обработки заключается в нанесении на поверхность деталей углеродосодержащей обмазки или покрытия, которое оплавляется под воздействием плазменной струи. Под действием газодинамической силы плазменной струи (дуги) происходит интенсивное перемешивание жидкого металла с углеродом и при последующей кристаллизации образуется легированный слой с большим количеством углерода [2,3]. В данных работах показано, что плазменная цементация из твердой фазы возможна только с оплавлением поверхности, т.е. образуется жидкая сварочная ванна. Это приводит к ухудшению шероховатости и искажению размеров обрабатывающих деталей. В работе [4] рассмотрен новый состав покрытия (графит, жидкое стекло, вода, масло-СОЖ) для нанесения на поверхности различных деталей машин и инструментов, который в сочетании с новым составом плазмообразующего газа (смесь аргона и углекислого газа) позволяет проводить насыщение поверхности металла углеродом без оплавления и с оплавлением поверхности.

Цель работы: Изучение микроструктуры цементируемых слоев, полученных после плазменной цементации без оплавления поверхности и влияния скорости нагрева и охлаждения на образованные микроструктуры.

\section{2. Материал и методики исследования}

Для четкого фиксирования явления поверхностного насыщения углеродом выбрали малоуглеродистые стали Ст3, сталь 20 не склонные к поверхностной закалке на высокую твердость [1]. В качестве твердого покрытия использовали пасту следующего состава: графит, жидкое стекло, вода, масло [4]. Для ускорения процесса насыщения применяется порошок с высокой дисперсностью частиц графита. Порошок графита получали шлифованием графитового электрода марки ГК-1 ГОСТ 4404-78. Массовая доля углерода составляла $0,95 \%$. Полученный порошок просеивался через сито с размером ячеи 0,08 мм. На рис. 1 приведена схема процесса изготовления графитового покрытия и последующей плазменной обработки.

\section{3. Результаты экспериментов и обсуждение}

После плазменной обработки на поверхности детали образуется белая полоса с высокой твердостью. Поверхность металла после плазменной обработки не оплавляется, ее шероховатость находится в пределах $\mathrm{Ra}<4$ мкм. При изучении шлифов в поперечном сечении под микроскопом зафиксирован цементированный слой глубиной 35-250 мкм в виде белого слоя, который имеет микротвердость от 5000 до 12000 МПа (при нагрузке 2 Н). На рис. 2 белый слой располагается по ширине дорожки упрочненного слоя.

Установлено, что микроструктура и микротвердость поверхностного слоя зависит от соотношения графита и жидкого стекла в покрытии, скорости охлаждения. Экспериментально показано, что в составе графитового покрытия оптимальный процент жидкого стекла находится в пределах от 30-83\%. Если процент жидкого стекла меньше 30\%, то прочность сцепления покрытия с металлом не достаточна, и оно отлетает с поверхности из-за действия на покрытия газодинамического давления плазменной дуги. Если процент жидкого стекла больше 83\%, то не наблюдается процесса насыщения углеродом поверхностного слоя металла.

После плазменной поверхностной обработки покрытия содержащего 60\% жидкого стекла в поверхностном слое стали Ст3, стали 20 образуется отбеленный слой (рис. 3a), в основном состоящий из четырёх подслоев: 1 - ледебурит, 2 - ледебурит + остаточный аустенит + мартенсит, 3 - остаточный аустенит + мартенсит, 4 - мартенсит. Металлографические исследования отбеленного слоя на стали Ст3 показали, что первый слой имеет структуру эвтектического белого чугуна. Основное затруднение в описание структур связано с избыточным цементитом, который представлен в виде пластин, которые визуально можно интерпретировать как иглы вторичного цементита видманштеттова типа (рис. 3d). Также наблюдаются массивные цементитные клубки, декорирующие межосевые промежутки бывших аустенитных дендритов. Цементитные клубки являются скоплением повышенного числа игл видманштеттова

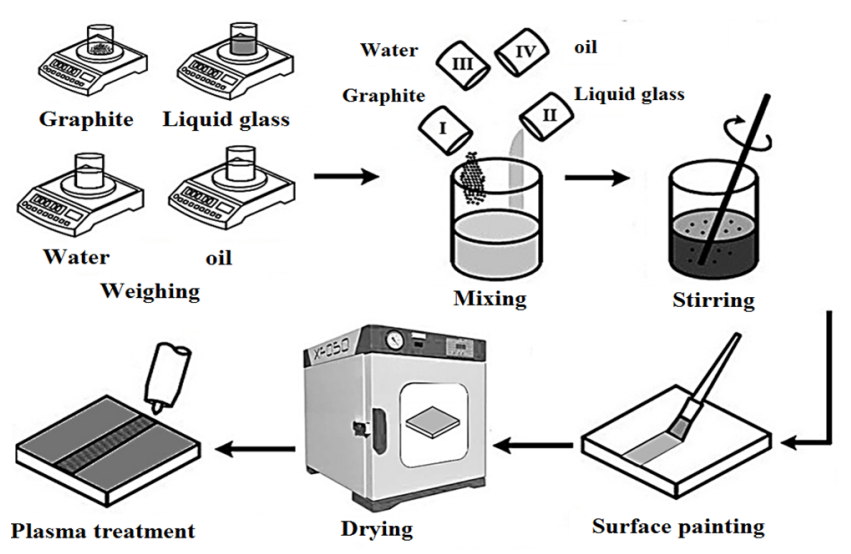

Рис. 1. Схема процесса плазменной цементации. Fig. 1. Scheme of plasma carburizing process. 


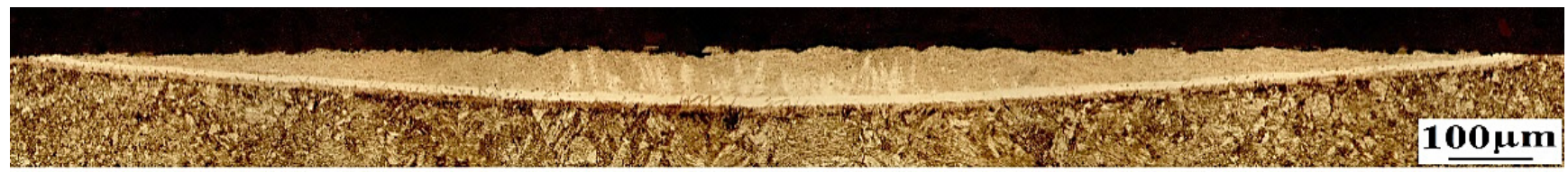

Рис. 2. Поперечный шлиф упрочненного слоя на стали Ст3.

Fig. 2. Cross section of the hardened layer on steel C3.

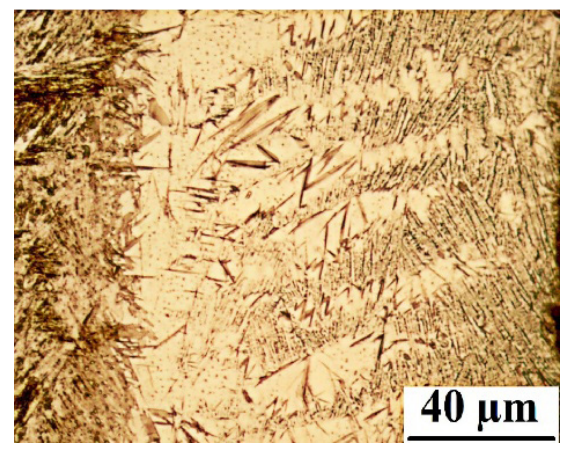

a

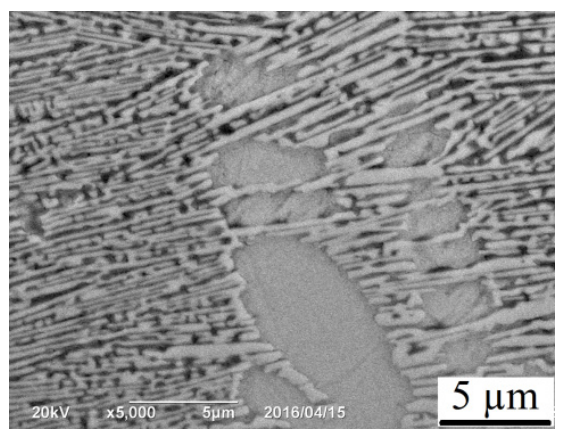

d

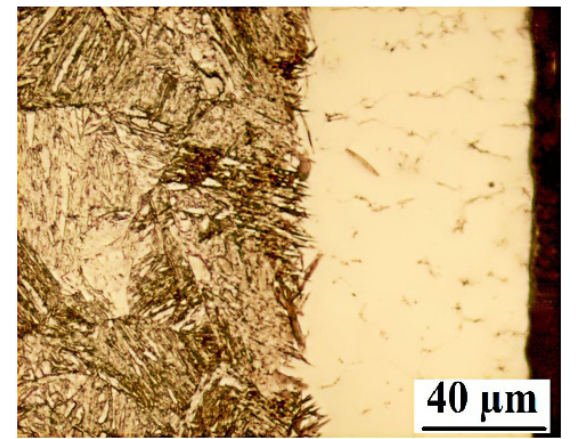

$\mathrm{b}$

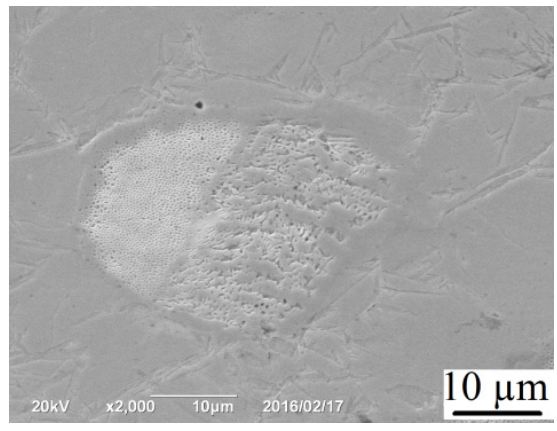

e
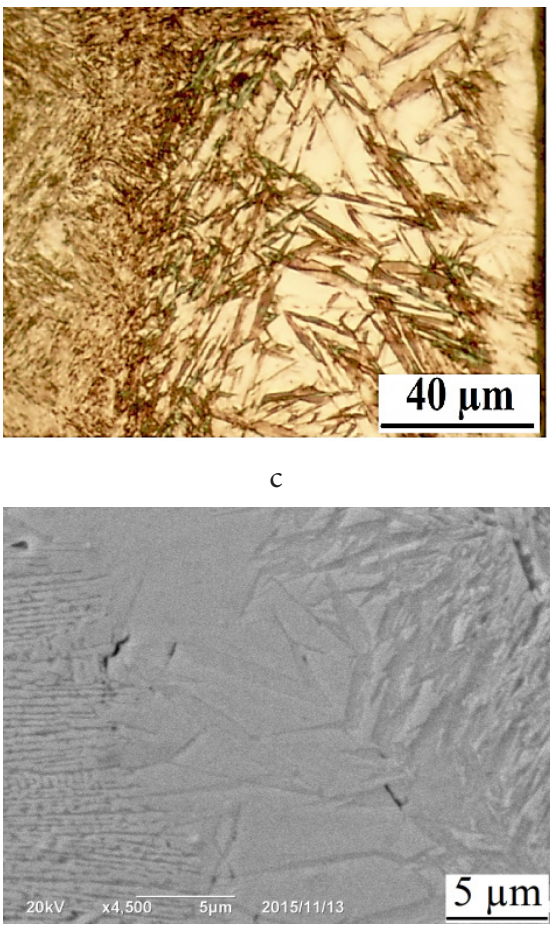

Рис. 3. Микроструктура цементируемого слоя: $\mathrm{a}, \mathrm{d}, \mathrm{e}, \mathrm{f}-60 \%$ жидкого стекла; $\mathrm{b}-80 \%$ жидкого стекла, $\mathrm{V}_{\text {охл. }}=1740^{\circ} \mathrm{C} / \mathrm{c}$; $\mathrm{c}-80 \%$ жидкого стекла $\mathrm{V}_{\text {охл. }}=3450^{\circ} \mathrm{C} / \mathrm{c}$.

Fig. 3. Microstructure of the cemented layer: $\mathrm{a}, \mathrm{d}, \mathrm{e}, \mathrm{f}-60 \%$ of the liquid glass; $\mathrm{b}-80 \%$ of the liquid glass, $\mathrm{V}_{\text {cooling. }}=1740^{\circ} \mathrm{C} / \mathrm{s}$; $\mathrm{c}-80 \%$ of the liquid glass, $\mathrm{V}_{\text {cooling. }}=3450^{\circ} \mathrm{C} / \mathrm{s}$.

цементита, выделевшиеся из твердого раствора с повышенной концентрацией углерода (рис. 3е). Ниже этого слоя появляются остаточный аустенит, реечный и пластичный мартенсит (рис.3f). Наличие большого количества остаточного аустенита снижает твердость данных слоев (слои 2, 3) [5].

С дальнейшим увеличением количества жидкого стекла в составе покрытия (до 80\%) и как следствие этого уменьшение содержания графита образуется уже отбеленный слой (рис. $3 \mathrm{~b}$ ), состоящий только из двух слоев: остаточный аустенит + мартенсит. Первый слой плохо травится и имеет низкую микротвердость 4000 - 5500 МПа. Большое количество остаточного аустенита указывает на недостаточность скорости охлаждения при плазменной поверхностной цементации [1]. С помощью программного комплекса Visual environment 8.6 мы определили ориентировочно скорость охлаждения при плазменной обработке [6]. Расчет показал, что при перемещения плазменной дуги со скоростью 5 мм/с на образце размерами $20 \times 80 \times 10$ мм максимальная скорость охлаждения составляет $\mathrm{V}_{\text {охл. }}=1740^{\circ} \mathrm{C} / \mathrm{c}$.
С повышением скорости перемещения плазменной дуги до $10 \mathrm{mм} / \mathrm{c}$, максимальная скорость охлаждения достигает $3450^{\circ} \mathrm{C} / \mathrm{c}$ и в упроченном слое появляется пластинчатый мартенсит, микротвердость составляет 5000 - 7500 МПа (рис. 3c). При увеличении скорости охлаждения до $5600^{\circ} \mathrm{C} / \mathrm{c}$, за счет уменьшения размеров пятна и увеличения коэффициента сосредоточенности [6] упрочненный слой состоит из игольчатого мартенсита с высокой твердостью 9000 - 11000 МПа (рис. 4a).

Электронно-микроскопические исследования структуры позволили уточнить тип структурных составляющих, формирующихся в зависимости от состояния аустенита и скорости его охлаждения, и определить особенности их внутреннего строения (рис. 3). Сравнительный анализ, полученных структур в упроченной зоне со структурами, полученными при традиционной термообработке и сварке чугуна $[5,7,8]$, высокоуглеродистых сталей показывает, что избыточный цементит в цементируемой зоне, может быть представлен, как в виде пластин в объеме остаточного аустенитного зерна, так и в виде сетки по границам аустенитного зерна и скоп- 

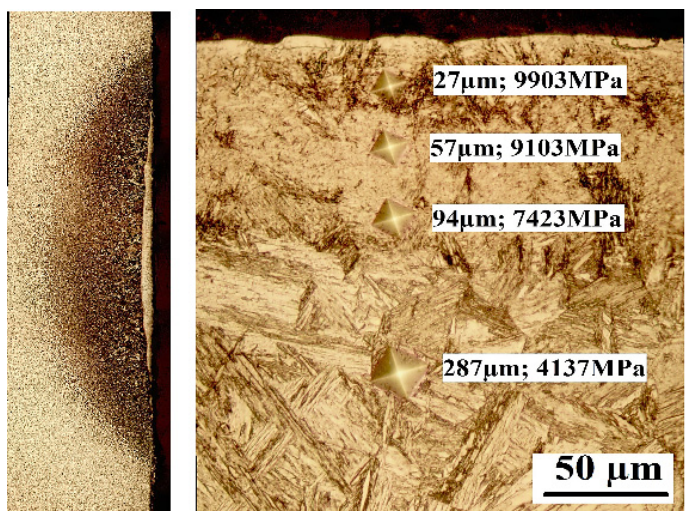

a
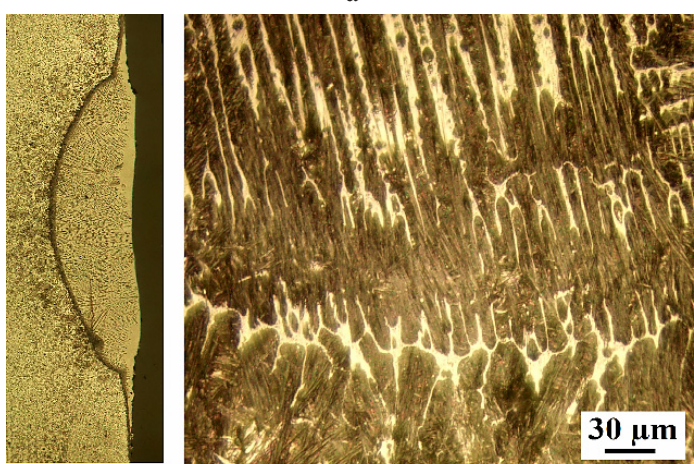

$\mathrm{b}$

Рис. 4. Микроструктура цементируемого слоя: a - 80\% жидкого стекла $\mathrm{V}_{\text {охл }}=5600^{\circ} \mathrm{C} / \mathrm{c} ; \mathrm{b}-\mathrm{c}$ образованием жидкой ванны металла.

Fig. 4. Microstructure of the cemented layer: a $-80 \%$ of the liquid glass $\mathrm{V}_{\text {cooling. }}=5600^{\circ} \mathrm{C} / \mathrm{s} ; \mathrm{b}-$ forming a liquid metal bath.

лений (клубков) ликвационной природы в межосевых промежутках дендритов аустенита. Отдельно можно выделить первичный цементит в составе неравновесного ледебурита. На рис. 5 представлены результаты измерения микротвердости по глубине цементированного слоя при обработке с покрытием $60 \%$ жидкого стекла. Результаты представлены в виде гистограмм, с измерением в нескольких точках для каждого значения в поперечном разрезе, с целью повышения достоверности результатов.

На рис. 5 показано распределение микротвердости поверхности образца после режима насыщения углеродом с промежуточной «мягкой» зоной (структура остаточного аустенита и мартенсита). Такой режим насыщения позволяет формировать градиентно структурно-фазовые состояния в поверхностном слое металла при плазменной поверхностной цементации, которые возможно рассматривать уже как композиционный материал $[1,2]$. Проведенный анализ экспериментальных данных позволил сформулировать несколько положений. На макро уровне, цементированный слой состоит из двух зон, где первая зона со значительным пересыщением по углероду (структура белого чугуна) формируется за счет фронтальной диффузии углерода (структура слоя: ледебурит, остаточный аустенит, мартенсит). Вто-

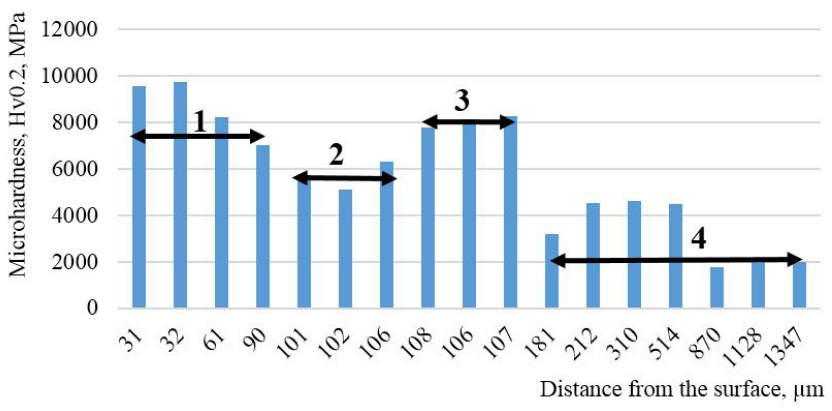

Рис. 5. Распределение микротвердости по глубине цементированного слоя с мягким внутренним слоем (60\% жидкого стекла): 1 - слой ледебурита; 2 - остаточный аустенит + пластинчатый мартенсит + ледебурит; 3 - пластинчатый + игольчатый мартенсит; 4 - зоны 3ТВ и исходная структура.

Fig. 5. Distribution of microhardness along the depth of the cemented layer with a soft inner layer (60\% of liquid glass): 1 - layer of ledeburite; 2 - retained austenite + plate martensite + ledeburite; 3 - plate + lath martensite; $4-$ HAZ zones and source structure.

рая зона формируется за счет интенсивной или реакционной диффузии, и концентрация углерода постепенно приближается к исходной. Зонное строение цементированного поверхностного слоя стали однозначно свидетельствует о градиенте концентрации углерода в стали. Наличие четких границ между зонами указывает о дискретном (кусочно-непрерывном) характере данного градиента [9], что должно сопровождаться различными физико-химическими свойствами и как следствие, влиять на прочность, вязкость, трещиностойкость, износостойкость поверхностного слоя в целом $[10,11]$.

Дополнительно к проведенным исследованиям по плазменной цементации в режиме микрооплавления покрытия были проведены работы в режиме макрооплавления поверхности. По нашему мнению образование большой и глубокой жидкой ванны в процессе плазменной поверхностной цементации позволяет значительно увеличить глубину цементации и упрочения в целом до 3-5 мм [2]. Тем самым, мы расширяем диапазон толщин рабочего слоя для дальнейшего применения данной технологии в промышленности, расширяем номенклатуру возможных деталей машин и инструментов где необходимо повысить износостойкость. Большая ванна расплавленного металла позволяет обеспечить более равномерное распределение углерода в упроченной дорожке. На рис. 4b приведен поперечный шлиф образца стали 20 после плазменной обработки с макро оплавлением поверхности (мощность плазменной дуги составляла 4 кВт). Видно, что в условиях режима плазменной цементации макро оплавления поверхности, глубина упрочения значительно увеличивается.

Проведенные нами исследования показали, что аустенит в цементированном слое имеет две морфологические разновидности. Первая морфологическая составляющая это свободные зерна остаточного аустенита, 
образующиеся в зоне внутренней цементации. Вторая морфологическая составляющая это прослойки и островки различной формы и размеров остаточного аустенита, присутствующие в структуре мартенсита или, наоборот, раздельные расположенными кристаллами мартенсита (в зависимости соотношения объёмных долей остаточного аустенита и мартенсита). Цементит присутствует, как в цементируемой зоне в виде отдельных самостоятельных зерен (глобул) различной формы и размеров, так и виде вторично и третичного цементита в структуре мартенсита, остаточного аустенита. Мартенситная составляющая цементированного слоя имеет несколько морфологических разновидностей и определяется содержанием углерода. В целом можно выделить две морфологические составляющие по содержанию углерода - кристаллы пакетного и пластинчатого мартенсита. Первая разновидность (пакетный мартенсит) формируется в зоне, находящейся в зоне термического влияния, где содержание углерода не превышает 0,6\%. Формирование пакета носит незавершенный характер. В этом случае в пакете зафиксированы прослойки остаточного аустенита вдоль границ кристаллов мартенсита. Вторая разновидность мартенсита (пластинчатый мартенсит) содержится непосредственно в цементированном слое где содержание углерода составляет более $0,6 \%$. Пластинчатый мартенсит представляет отдельно расположенные кристаллы $\alpha$-фазы разделенными прослойками или островками аустенита. Разновидностью пластинчатого мартенсита является линзовидный мартенсит, образующийся в цементированном слое.

В заключении необходимо отметить, что в прикладном аспекте рассмотренная в данной работе технология плазменной поверхностной цементации по глубине и микротвердости поверхностного слоя не уступает вакуумной и ионной цементации металлов $[7,8]$. В настоящий момент данный способ по времени насыщения поверхностного слоя углеродом (в течении 0,1-1 сек) является самым производительным, что открывает широкие перспективы для внедрения его в промышленности. Таким образом, представленные выше результаты показывают возможность осуществления поверхностной плазменной цементации, где важным параметрами является состав цементирующей пасты (обмазки) и скорость охлаждения поверхностного слоя металла. Вместе с тем необходимо в дальнейшем провести дополнительные исследования по уточнению основных закономерностей насыщения поверхностного слоя углеродом, отработке технологических параметров, проведению испытаний на износостойкость и трещиностойкость цементированных деталей машин и инструментов.

\section{4. Выводы}

1. Установлено, что в процессе плазменной обработки поверхности металла с нанесенной на нее углеродосодержащей пастой, происходит насыщение поверх- ностного слоя углеродом как в режиме с оплавлением поверхности, так и без оплавления. Длительность насыщения поверхностного слоя металла углерода составляет $0,1-1 \mathrm{c}$.

2. Показано, что в зависимости от режимов плазменной обработки, возможно, получать цементированные слои на поверхности изделия в диапазоне от 35 до 250 мкм и микротвердостью до 12000 МПа.

\section{Литература/References}

1. A.E. Balanovskii. Strengthening Technologies and Coatings. 1 (133), 25-34 (2016) (in Russian) [Балановский А.Е.. Упрочняющие технологии и покрытия. 1 (133), 25 - 34 (2016)]

2. A.E. Balanovskii. Plasma surface hardening of metals. Irkutsk, Publishing House of IrSTU (2006) p 180. (in Russian). [А.Е. Балановский. Плазменное поверхностное упрочнение металлов, Иркутск: Изд-во ИрГТУ. 2006. 180 c.]

3. A.A. Skripkin, V.A. Netsvetaev, V. E Shcherbakov, N. Yu. Minenko. Welding International. 11, 15-17 (1992) (in Russian) [Скрипкин А.А., Нецветаев В.А., Щербаков В.Е., Миненко Н. Ю. Сварочное производство. 11, 15 - 17 (1992)]

4. Vu Van Huy., A.E. Balanovskii. Innovations in Science. 51-1, 95-102 (2015) (in Russian) [Ву Ван Гюи., Балановский А.Е. Инновации в науке. 11, 15-17 (2015)]

5. A.N. Minkevich.Chemical-thermal treatment of metals and alloys, Moscow, Mechanical engineering (1965) 492p. (in Russian) [А.Н. Минкевич Химико-термическая обработка металлов и сплавов. М., Машиностроение, 1965. 492 c.]

6. A.E. Balanovskii, Vu Van Huy. Strengthening Technologies and Coatings. 146 (2), 82-91 (2017) (in Russian) [Балановский А.Е., Ву Ван Гюи. Упрочняющие технологии и покрытия. 146 (2), 82-91(2017)]

7. Y.Sun. Journal of Materials Processing Technology. 168, $189-194$ (2005)

8. CJ Scheuer, RP Cardoso, FI Zanetti, T Amaral, SF Brunatto. Surface and Coatings Technology 206 (24), 5085 - 5090 (2006).

9. N.R. Gal, E. V Rutkov, A. Ya Tontegode. Technical Physics. 72 (4),113 - 119 (2002) (in Russian) [Галь Н. Р., Рутьков Е.В., Тонтегоде А.Я. Диффузия углерода между объёмом и поверхностью (100) молибдена // ЖТФ.72 (4),113 - 119 (2002)]

10. Vu Van Huy, A.E. Balanovskii,. Vestnik IrGTU. 21 (3), 10-22 (2017) (in Russian) [Ву Ван Гюи, Балановский А.Е.,. Вестник ИрГТУ. 21 (3), 10-22 (2017)]

11. $\mathrm{Vu}$ Van Huy, A.E. Balanovskii,. Vestnik IrGTU. 21 (4), 10-21 (2017) (in Russian) [Ву Ван Гюи, Балановский А.Е.,. Вестник ИрГТУ. 21 (4), 10-21 (2017)] 